\title{
Enterprise Architecture “As-Is” Analysis for Competitive Advantage
}

\author{
A Case Study of the Internet Service Provider Company
}

\author{
Eithar Mohamed Mahmoud Nasef ${ }^{1}$, Nur Azaliah Abu Bakar ${ }^{2}$ \\ Razak Faculty of Technology and Informatics \\ Universiti Teknologi Malaysia \\ 54100 Kuala Lumpur, Malaysia
}

\begin{abstract}
In the telecommunication market, it is essential to ensure that the infrastructure and resources of the internet service provider can adapt and grow. In contrast, provide the best quality of data services and offering the best packages for their customers. It is essential to ensure that an internet service provider company remain competitive and agile so that it can provide better products and services promptly to the market. At iiNET, raising awareness of how having an enterprise-wide understanding and view of how the business processes run and all the existing technology within the organisation is vital in ensuring their adaptability and growth in the telecom industry. This paper discusses the challenges which IINET is currently facing and how an enterprise architecture solution is proposed to provide iiNET with the strategic advantage it needs to overcome those challenges. The existing EA frameworks are discussed and analysed to select the best fit for iiNET's EA solution. Finally, the "As-Is" architecture at iiNET is explained as the findings for this EA implementation phase.
\end{abstract}

Keywords-Enterprise architecture; internet service provider; competitive advantage; “As-Is” analysis

\section{INTRODUCTION}

Today, technology has enabled a fast-paced environment where integration between business and systems has become an essential part of an organisation's success. Technology has allowed for a much higher level of integration between old and new architectures, to support all levels of functions in a business [1]. The problem that is currently faced is that there is clear segregation between the IT implementation in an organisation and its department. Each department is either using their own isolated IS or not at all. This often causes a weak communication between communications between departments as well with systems outside the organisation [2].

The top telecommunication leaders in the industry can achieve this because, they have a clear understanding of data flows in the organisation, applications capabilities and infrastructure across of their business units [3]. That is, they, at all times, have a precise enterprise-wide view of the business, operations and all the technologies underlying it. This can be achieved by forming competitive advantage strategies that allow a company to produce goods or services better or more cheaply than its rivals. The competitive advantage is linked to a variety of factors, including pricing structure, brand marketing, product quality, customer base, intellectual property and customer care. To build an impactful competitive advantage strategy, it often combines with competitive intelligence that refers to the ability to collect, evaluate and use the knowledge gathered about rivals, consumers and other market factors [4]. This is where it can be synergised with Enterprise Architecture (EA) as it aligns the organisations business process to its strategic goals and supported by its technologies.

EA is a holistic strategy that is used to increase the alignment of the enterprise's business and Information Technology [5]. EA gives a blueprint for creating enterprisewide information systems" to achieve its business objectives systematically. There exist different frameworks of EA application, all mainly consist of the following four main layers: business, data, applications and technology infrastructure. These layers describe how the information systems, processes, organisational units and people in an organisation function as a whole. EA ensures that the layers are integrated to drive the organisation's strategic goals, ensuring alignment between business and IT.

Ultimately, EA is a systematic structure or taxonomy of system analysis models to match organisational strategy with IT. However, EA implementation is not an easy process, as it requires support from both business and IT personnel[6]. There is resistance towards EA implementation from management as well as employees due to unclear expectation. In some cases, EA implementation becomes ineffective due to the complexity associated with EA implementations of practices, models and strategy. Due to this increased complexity and failing to realise the benefits that EA brings it causes a lack of support from shareholders and failure to accept and change.

This paper will describe the role of competitive advantage and competitive intelligence strategy in EA implementation at a large internet service provided company. The scope of this paper is on the EA design process, and it will explain how they are mapped together. At the end of the paper, the "As-Is" architecture findings of the case study are presented.

\section{LITERATURE REVIEW}

EA is a blueprint for identifying the structure and functioning of organisations with an extensive framework or taxonomy for system analysis models to align organisational strategy with IT. There are many EA frameworks exists 
according to the need of the organisation, and among the widely adopted structures are TOGAF, Zachman EA Framework and EA3Cube, which will be described in the following subsections

\section{A. Enterprise Architecture Framework}

1) The Open Group Architecture Framework (TOGAF): TOGAF is a framework which focuses on Enterprise Continuum with the Architecture Development Method (ADM). It was developed in 1995 by The Open Group. TOGAF is an open-source framework. It provided an organisation with the tools and methods needed to build Enterprise architecture [7]. There are several strengths of TOGAF that attracts much organisation to adopt this framework for their EA implementation. Some of the strength is; TOGAF allows a cost-efficient way for any organisation to implement EA as it uses a simplified approach to design, plan, acquire, and integrate the IT architecture to the business. It is flexible and adaptable and more practical to use than other existing framework solutions. TOGAF is also an open framework and freely accessible to anyone. Another advantage of TOGAF is, it is supported by a large community which portrays the credibility of the framework itself.

However, there is are also some limitation of TOGAF as discussed by previous studies. Firstly, TOGAF is not tightly integrated, and the existing material is comprehensive [8]. Despite being public, there are not many available TOGAF implementations freely available as it is considered the company privacy asset [9]. It can be vague and not as prescriptive and measurable. Therefore, this makes it harder to implement, especially for the beginner[10]. Thus, in many cases, experienced enterprise architects are needed to design such frameworks, as there is still scarce of guidance available, especially for the solution architects role.

2) The zachman framework: The Zachman framework, despite its name, is less of a framework and more of an ontology used in the structure of an EA. This ontology provided a formal and structured way of and defining an enterprise and has been employed in many large organisations, and proven to work by Zachman's experience himself [11]. The Zachman framework(ontology) is made up of a twodimensional classification schema or a $2 \times 2$ matrix that reflects the intersection between two historical classifications [11]. The first is rudimentary: data (what), function (how), network (were), people (who), time (when) and motivation (why). The second is the ontological principle of reification, the conversion of an abstract idea into an instantiation. The transformations under Zachman Framework are description, concept, representation, specification, configuration and instantiation of what, how, who, when, and why in the designing of information system roles (or perspectives). The Zachman framework reification transformations are identification, definition, representation, specification, configuration and instantiation of the what, how, where, who, when and the why based on the roles (or perspectives) involved in information systems design [11].
Based on previous studies, the strength of the Zachman framework is that it allows different stakeholders ranging from business until technical personnel to look at the same thing from different perspectives [12, 13]. Thus, it efficiently creates a holistic view of the environment. This framework also is an excellent tool for determining the taxonomy of an enterprise [14]. Nevertheless, the Zachman framework also has some significant drawback, such as no step-by-step procedure for creating a new architecture, which resulted lost in the architecting process[15]. Furthermore, there is a lack of analysis to validate either the proposed future architecture is improving the current architecture[16]. Therefore, it falls short at prescribing detailed solutions for enterprise problems and often implies solutions that are too idealistic and less realistic.

3) EA3 cube framework: EA cube is a framework explaining the different components and layers within the framework. Scott Bernard created the EA 3 Cube in 2004, and iEAi owns EA3 [17]. It is based on the concept: "EA=Strategy+Business+Technology"; whereby the purpose of EA3 Cube framework is to transform an enterprise from its current state to a future desired state. The five layers in EA3Cube are: 1) Goals and Initiatives, 2) Products and services, 3) Data and Information, 4) Systems and Applications, 5) Networks and Infrastructure[17].

Previous studies highlighted some positive remarks on EA3Cube as this framework uses EA's primary organising and planning IT resources and documentation. It will also still comply with the organisation's vision [18]. Another advantage is that it is a simple framework and can be easily applied [19]. Meanwhile, there is also a limitation of EA3Cube as it is more suited to be used by small and medium-sized organisations compared to the large organisation [20]. Since it is also a proprietary framework, the cost of maintaining the current infrastructure can be a liability [15].

\section{B. Competitive Advantage Concept}

Competitive advantage applies to conditions enabling a business to manufacture products or services more or cheaper than its competitors. These factors allow a competitive company to produce more revenue or profits than its industry rivals [21]. Competitive advantages are attributed to various factors, including cost structure, branding, product quality, distribution network, intellectual property, and customer service [22]. Due to specific strengths or conditions, competitive advantages generate higher value for a firm and its shareholders. The more sustainable the competitive advantage, the harder it is for competitors to neutralise the advantage.

Competitive intelligence refers to the ability to collect, interpret and use the information on rivals, consumers and other market indicators that contribute to the competitive advantage of a company [23]. Economic knowledge is crucial because it lets firms understand their strategic climate and the prospects and challenges, hence allow businesses to analyse information for efficient business practices [24]. Competitive intelligence can be grouped into two main silos: tactical and strategic. Tactical intelligence is short-term and seeks to contribute to issues like capturing market share or increasing 
revenue. Meanwhile, strategic intelligence focuses on longterm issues like key risks and business opportunities.

\section{Case Study Background}

iiNET is a telecom company based in Australia which provides internet access services. Over the past couple of years, iiNET has lost $15 \%$ of its business profitability and facing many challenges it retaining its customers. The shareholders have been placing much pressure on the CEO of iiNET to make a change to the organisation to gain a strategic advantage over its competitors. Thus, the CEO tool the initiative along with the top management to look into an EA solution to align business and IT for competitive advantage in the marketplace [25]. Reports at iiNET revealed that due to inefficient business processes and IT infrastructure that could not keep up with the market internet access services provided.

The challenges that iiNET is facing include: 1) Losing customers to other new rise-up telecom companies; 2) Inefficient operations causing the lack of meeting the business goals; 3) The different network locations are not well maintained in some locations creating bad service as some locations.; 4) Other telecoms offering much faster data service and 5)Urgent need for an updated architecture that is robust enough to handle continued growth and can meet the needs of future regulatory requirements. To resolve these uprising issues, iiNET wants an enterprise solution which will help the organisation build the necessary strategic capability to allow it to gain a competitive advantage in the market. Through this implementation, iiNET is looking forward to introducing a method and tool that will guide in defining and governing their implementation while having a connected repository of the EA.

\section{EA DESIGN METHODOLOGY}

In the initial stage, to choose the right EA framework, a study of the existing EA framework is done to evaluate the strength and weakness of each of the frameworks. In the second stage, a SWOT analysis is used to identify the strengths and weaknesses of the organisation which will help in choosing the right EA framework for the right situation and understand the strategic, political, innovation and cultural factors at iiNET. Once the study has been made, and analysis of the feasibility of the EA frameworks is done by using the result of the SWOT analysis as it helps understand the people, processes and technologies at iiNET and to select the most effective framework to support that. Fig. 1 shows the SWOT analysis performed at iiNET in choosing the suitable EA framework for implementation.

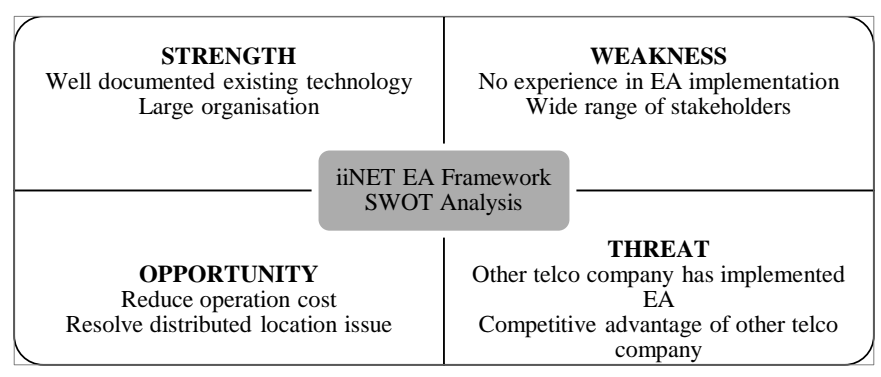

Fig. 1. iiNET EA Framework SWOT Analysis.
The strategy at iiNET is to reduce costs and document existing technologies to understand where to improve. Strategically, iiNET is concerned with aligning its business and IT operations and infrastructure to improve its service quality. Because iiNET has never implemented EA practices in the organisation before, it is essential to select an EA framework that not only provides a definition and conceptualisation of the framework but will provide a complete and detailed process to guide them into how to implement and know what to do next. It is also essential to select an EA framework that has been proven in the Telco industry to be a success for the organisation with no history of EA implementation and is just starting.

After evaluating the above frameworks, and reviewing the organisation's strength and weaknesses, the best fit selected to be used at the EA framework is the TOGAF framework used to build a successful architecture by iiNET to achieve rapid EA development utilising a cost-effective way. TOGAF has a set of defined approaches used to propose and direct the methodology and architecture. The next section will further describe how TOGAF is used to analyse the existing ("As-Is") architecture layers at iiNET.

\section{RESUlts AND Discussions}

Based on a study by [26], every layer in EA can be aligned with a competitive advantage. Both EA and competitive advantage support the same vision and mission of the organisation. The relationship between competitive advantage, competitive intelligence and EA is shown in Fig. 2. Following, the "As-Is" findings in iiNET will be discussed according to Fig. 2.

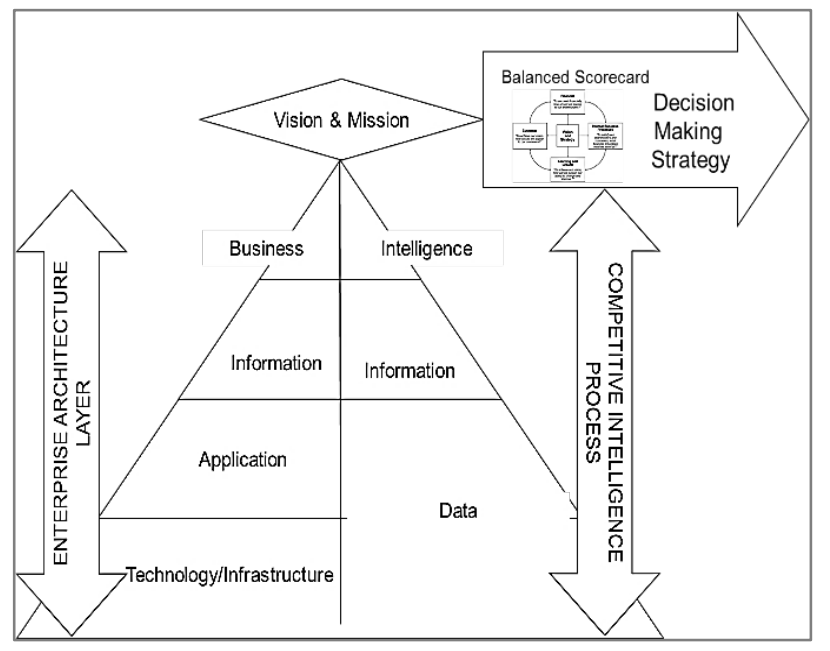

Fig. 2. The Relationship between EA and Competitive Advantage/Intelligence [26].

\section{A. Business Architecture}

iiNET's vision is to become the leading telco company for internet data services in Australia. The goal is to be the leader in providing the fastest and most stable internet accessibility. Initially, iiNET can provide internet services to its customer, which at the time was considered sufficient. However, the telco industry has grown over the years, with many new entrants offer better and faster internet services. For iiNET to 
compete, it needed to match up to that be provide even better services for customers. In iiNET, the main business functions which need to be aligned together are the customer relationship management, the telecom network resource management and lastly the partner relationship management. Aligning the above ensures the delivery of better internet data services using a systematic and efficient delivery model, ensuring service quality for customers.

Currently, iiNET is facing many challenges in its telecom network management. It is not able to maintain the infrastructure needed to provide internet networks for its customers. This resulted in service outages as well as slowness with caused much dissatisfaction in the customers. To tackle this challenge, the EA solution provided will bring value from each of the business processes. This is done through aligning iiNET's vision to its goals. When updating the goals and initiatives, value (including ROI) is defined in each of the business processes, and the reference architecture, which provides a template architecture and a common vocabulary is developed. This is to provide a common language that will be used to address all levels of the architecture.

\section{B. Data Architecture}

iiNET has been using the traditional commonly used Operational and Business Support Systems (OSS/BSS) for managing the business processes. These systems required much data gathering and shared data to serve the customers. The issue with these systems is that they have an existing integrating technology that makes it difficult to communicate with the data and result in much work to standardise data and information as it has their collection of data types and format, so a transition model was thus required to turn information and data into a unified framework. This resulted in much time consumed to do basic reporting and to understand and analyse the data reported. This made data inconsistent at some stages, which resulted in inaccurate data reaching the stakeholders at iiNET. Without accurate data, iiNET is unable to evaluate their finances and business process measures correctly.

On the data architecture layer, the EA solution provided offers a standardised data collection, storage and reporting tools for gathering and modelling data from all levels of the EA and stored it a common repository for access when needed. This ensures the data quality and consistency, and infrastructure optimisation with a greater emphasis on business integration. The EA solution offers EA process artefacts and standardised templates for reporting as well as metrics and performance measurement for reporting.

\section{Application Architecture}

iiNET's conventional OSS/BSS covers all operating systems used by internet service providers to control Billing Support Systems (BSS) telco network. This includes all systems dealing with customer service and maintaining customer relationships providing services like bill processing, payment collection, among others. These systems can no longer satisfy the TSP's need to deliver new value-added services or service bundles at a rapid pace to fight churn and ensure higher average revenue per user. iiNETS new OSS / BSS platforms are expected to leverage several architectures and networks and provide different services, including datadriven service scoring, billing and customer care.

With the EA solution offers an integrated OSS/BSS systems solution. This is done by using an integrated application queue based upon the standardised business processes. The customer relationship management system, telecom network resource management system and partner relationship management system are all integrated as one pool of systems, and it is using connectors to link to an integrated system application view. This means that employees only need to access the one systems to be able to access the services of underlying integrated systems. This solution also offers a customer-facing web application for processing subscription, billing, payments processes and more.

\section{Technology Architecture}

Initially, these traditional OSS/BSS systems were mainframe-based, stand-alone systems designed to support staff members in their daily jobs. This posed a problem that a minor improvement in one device might affect all interfaces. This significantly increased the complexity of the systems. Furthermore, iiNET's existing network infrastructure that is distributed across the different location is not well maintained. iiNET is unable to keep track of the infrastructure management process.

Fig. 3 shows the overall EA “As-Is” findings for iiNET as discussed.

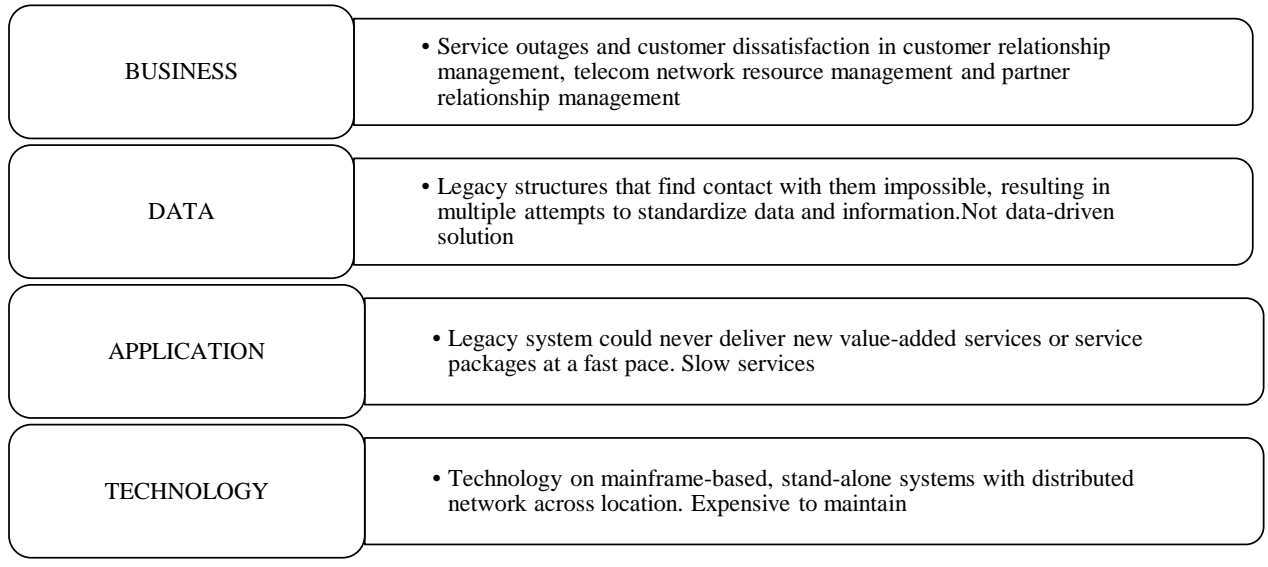

Fig. 3. EA based "As-Is" Findings for iiNET. 
The EA “As-Is" analysis and framework mapping allow the identification of the right supporting technologies required the various systems in iiNET. Currently, the solution used for gathering and defining all IT related domains and assets related to business processes were captured in IBM Rational System Architect Platform, which later can be translated into a new "To-Be" architecture of iiNET.

To validate the findings, a set of questions were designed for the respondents from various departments across the iiNET that involved in this "As-Is" data collection. There are six questions asked, with the Likert scale 1 to 5 (1-strongly disagree to 5-strongly agree):

1) Do you agree.with the overall "As-Is" findings?

2) Do you agree.with the Business "As-Is" findings?

3) Do you agree.with the Data "As-Is" findings?

4) Do you agree.with the Application "As-Is" findings?

5) Do you agree.with the Technology "As-Is" findings?

6) Do you agree.with that this "As-Is" findings able to highlight the existing competitive advantage/intelligence??

A total of 26 responds were collected from the survey. The validation results stated that the mean for each question are between 3.96 until 4.56 which indicates that the "As-Is" findings are valid and can be used for the next stage, which is "To-Be" phase.

With the future EA solution, the strategic mapping and compliance can also be carried out to determine the level of standardisation and optimisation of the resources in a large organisation like iiNET. Furthermore, with well-defined architecture principles that were derived from competitive advantage, exercise will be able to revise the existing business process and introduce several new initiatives with minimal efforts.

\section{CONCLUSION}

With the current state that iiNET was in, they required an enterprise architecture solution which out helps them overcome the challenged that was causing them to fall behind in the telecom industry. Using the TOGAF framework, an EA solution was designed, providing a description blueprint of the business, data, application, and technology architectures at iiNET. Not only is the EA solution providing next-generation solutions, but it has also allowed iiNET to use its existing legacy systems, modifying them, and integrating them other systems in the ways needed to meet their needs.

For future works, it is suggested to design a "to-be" solution that utilized on the module-based connector solution. This will provide an integrated solution for fulfilling all business processes when changes are made in any of the modules, they quickly integrated into system layer, ensuring that systems running below are not affected. In conclusion, for iiNET to continue to grow in the telecom industry, it must ensure that it has a thorough understanding of all its business processes and IT landscape to ensure that their technology and application infrastructure is aligned with and meetings the business goals.

\section{ACKNOWLEDGMENT}

Highest appreciation to the iiNET Limited for supporting this study. The research is financially supported by Universiti Teknologi Malaysia under Q.K130000.3556.06G26.

\section{REFERENCES}

[1] J. Cowan and L. B. Eder, "The transformation of AT\&T’s enterprise network systems group to Avaya: enabling the virtual corporation through reengineering and enterprise resource planning," Journal of Information Systems Education, vol. 14, no. 3, p. 15, 2020.

[2] T. Widjaja and R. W. Gregory, "Monitoring the Complexity of IT Architectures: Design Principles and an IT Artifact," Journal of the Association for Information Systems, vol. 21, no. 3, p. 4, 2020.

[3] A. I. Al-Alawi, "Customer Relationship Management: The Application of Data Mining Techniques in the Telecommunications Sector."

[4] L. Sun and Y.-z. Wang, "Identifying the core competitive intelligence based on enterprise strategic factors," Journal of Shanghai Jiaotong University (Science), vol. 20, no. 1, pp. 118-123, 2015.

[5] N. A. A. Bakar, S. Harihodin, and N. Kama, "Enterprise architecture implementation model: Measurement from experts and practitioner perspectives," in 2016 4th IEEE International Colloquium on Information Science and Technology (CiSt), 2016, pp. 1-6: IEEE.

[6] H. Sallehudin, N. S. M. Satar, N. A. A. Bakar, R. Baker, F. Yahya, and A. F. M. Fadzil, "Modelling the enterprise architecture implementation in the public sector using HOT-Fit framework," International Journal of Advanced Computer Science and Applications, vol. 10, no. 8, pp. 191198, 2019.

[7] O. Group. (2011). TOGAF 9.1: The Open Group Architecture Framework Version 9.1.

[8] C. Gebayew and A. A. Arman, "Modify TOGAF ADM for Government Enterprise Architecture: Case Study in Ethiopia," in 2019 IEEE 5th International Conference on Wireless and Telematics (ICWT), 2019, pp. 1-6: IEEE.

[9] B. Rezkita, R. Andreswari, and R. Hanafi, "Analisis Perancangan Enterprise Architecture Fungsi Pelaporan Wajib Pajak Bendaharawan Direktorat Jenderal Pajak Menggunakan Togaf Adm," eProceedings of Engineering, vol. 6, no. 1, 2019.

[10] N. H. Harani, A. A. Arman, and R. M. Awangga, "Improving togaf adm 9.1 migration planning phase by ITIL v3 service transition," in Journal of Physics: Conference Series, 2018, vol. 1007, no. 1, p. 012036: IOP Publishing.

[11] J. Zachman, "The Zachman framework for enterprise architecture," ed: Zachman Framework Associates Virginia, 2006.

[12] D. Leonard and J. F. Andry, "Redesign The Heavy Equipment Company's Business Processes Based on EAP Using The Zachman Framework," International Journal of Open Information Technologies, vol. 7, no. 12, 2019.

[13] S. D. Granita, I. Sabrina, F. Y. A. Hidayatullah, and A. Hanani, "Enterprise Architecture Zachman Framework in Ma’had Sunan Ampel Al'aly," in Proceedings of the International Conference on Green Technology, 2019, vol. 10, pp. 37-43.

[14] L. Davinci and J. F. Andry, "Designing Enterprise Architecture Planning Using the Zachman Framework," Inform: Jurnal Ilmiah Bidang Teknologi Informasi dan Komunikasi, pp. 14-19, 2020.

[15] T. Westbrock, "Do Frameworks Really Matter," EADirections, ww. eadirections. com/.../EAdirections\% 20Frameworks\% 20Breakout\% 20updated. pdf (2007, Oct. 24), 2009.

[16] B. Robertson-Dunn, "Beyond the Zachman framework: Problemoriented system architecture," IBM Journal of Research and Development, vol. 56, no. 5, pp. 10: 1-10: 9, 2012.

[17] S. Bernard, "Using enterprise architecture to integrate strategic, business, and technology planning," Journal of Enterprise Architecture, vol. 2, no. 4, pp. 11-28, 2006.

[18] N. Aljlayel, "Holistic Enterprise Architecture Frameworks (HEAFs)," Trends in Applied Sciences Research, vol. 11, no. 2, pp. 33-43, 2016. 
[19] R. Cloutier and D. Verma, "Applying pattern concepts to systems (enterprise) architecture," Journal of Enterprise Architecture, vol. 2, no. 2, pp. 34-50, 2006.

[20] B. A. Wubawa, V. H. Kusumawardhana, and H. L. H. S. Warnars, "Information System Strategic Planning at PT Eonchemicals Using the Framework EA3 Cubes," in 2018 Indonesian Association for Pattern Recognition International Conference (INAPR), 2018, pp. 250-255: IEEE.

[21] W. C. Johnson and A. Sirikit, "Service quality in the Thai telecommunication industry: a tool for achieving a sustainable competitive advantage," Management Decision, 2002.

[22] M. Gyemang and O. Emeagwali, "The roles of dynamic capabilities, innovation, organizational agility and knowledge management on competitive performance in the telecommunication industry," Management Science Letters, vol. 10, no. 7, pp. 1533-1542, 2020.
[23] H. S. Tooranloo and S. Saghafi, "Investigating the Impact of Using Knowledge Management on Organisational Agility through Competitive Intelligence and Strategic Thinking," Journal of Information \& Knowledge Management, vol. 18, no. 02, p. 1950016, 2019.

[24] V. Zenaide and L. T. e Castro, "Scenario of business practices in competitive intelligence within the telecommunication industry," African Journal of Business Management, vol. 9, no. 6, p. 311, 2015.

[25] iiNET. (2020). iiNET Business News. Available: https://www. businessnews.com.au/Company/iiNet.

[26] N. A. A. Bakar, S. Harihodin, and N. Kama, "Thriving For Government Competitiveness Intelligence Through Enterprise Architecture Process Assessment," in Knowledge Management International Conference (KMICe) 2014, Langkawi, Malaysia, 2014, vol. 1, no. 1: UUM. 